\title{
SISTEM PENDETEKSI DINI KEBAKARAN GEDUNG BERBASIS ZIGBEE MESH NETWORK
}

\author{
Ponco Wali Pranoto ${ }^{1}$, Rovadita Anggorowati ${ }^{2}$ \\ Pendidikan Teknik Elektronika Fakultas Tenik Universitas Negeri Yogyakarta \\ E-mail: poncowali@uny.ac.id , rovadita.anggorowati@yahoo.com
}

\begin{abstract}
ABSTRAK
Perkembangan teknologi khususnya dalam hal informasi dan komunikasi menjadi peran penting dalam dunia masa kini, sebagai contoh penerapan teknologi informasi dan komunikasi telah merambah dalam segala aspek kehidupan diantaranya ialah rumah tangga, otomotif, militer, kesehatan, industri, hingga lingkungan. Salah satu contoh perkembangan teknologi informasi dan komunikasi saat ini ialah wireless sensor network (WSN) yang mana pengembangan dan penelitiannya masih sangat terbuka lebar. Pada penelitian ini peneliti membangun sebuah sistem deteksi bahaya kebakaran dengan mengimplementasikan Zigbee Mesh Network berbasis wireless sensor network (WSN). Untuk sensor pendeteksi bahaya kebakaran yang digunakan adalah LM35, dan MQ-2 selain itu untuk komunikasi wireless nya menggunakan modul Xbee S2. Node sensor yang dibangun langsung terghubung antara modul Xbee dengan sensor LM35 dan MQ-2. Hasil dari pembacaan sensor akan dikirim ke koordinator dan diolah di Arduino. Kemudian data yang telah diolah akan ditampilkan pada antarmuka yang dibuat menggunakan aplikasi Visual Studio. Dari sistem yang telah dirancang mampu bekerja tanpa mikrokontroller untuk node sensor karena hanya melakukan pembacaan ADC dan digital. Sistem dapat bekerja dengan baik apabila jarak node dengan koordinator $<40 \mathrm{~m}$. Selain itu proses pengiriman data tidak terganggu apabila salah satu node sensor mengalami gangguan.
\end{abstract}

Kata kunci: LM35, MQ-2, Xbee S2, WSN

\section{PENDAHULUAN}

Seiring dengan perkembangan zaman, pembangunan akan gedung-gedung semakin menjulang tinggi. Dengan pembangunan tersebut dibutuhkan suatu sistem keamanan khususnya dari bahaya kebakaran untuk menghindari jatuhnya korban jiwa maupun luka-luka. Selain menghindari adanya korban, tak dipungkiri besarnya kerugian material yang diakibatkan apabila kebakaran telah terjadi dan menyebar luas hingga ke seluruh bagian ruangan gedung. Maka dari itu dibutuhkan suatu sistem pendeteksi kebakaran dini untuk menghindari korban dan mendeteksi lokasi sumber kebakaran pada setiap ruangan gedung.

Sistem pendeteksi dini kebakaran dapat dibangun dengan menggunakan sensor asap dan api untuk merasakan perubahan keadaan suhu dan adanya asap. Karena sensor hanya dapat mendeteksi pada lingkungan dimana sensor tersebut berada maka setiap sensor memiliki keterbatasan jangkauan dan tidak mampu satu sensor untuk menjaga keamanan seluruh ruangan gedung. Maka untuk membangun sistem pendeteksi dini kebakaran dibutuhkan penyebaran sensor pada setiap ruangan gedung. Dengan adanya penyebaran sensor, keamanan setiap ruangan gedung dapat terjaga.

Perkembangan teknologi seperti Wireless Sensor Network (WSN) saat ini sangat berkembang pesat (Firdaus, 2014). Proses pengiriman data secara wireless dan pemantauan jarak jauh tanpa peneliti harus berada dilokasi tempat sensor berada membuat teknologi WSN sangat diminati untuk diteliti dan dikembangkan. Penelitian-penelitian dilakukan guna menambah nilai fungsi dari WSN terutama dalam hal membangun sebuah sistem yang besar namun hemat energi. Salah satu perkembangan dari WSN ialah adanya Zigbee Mesh Network yang mana dirancang khusus untuk pembaangunan sistem skala besar dengan pengiriman data secara multi-hop (estafet) sehingga dapat menghemat energi lebih besar dari teknologi WSN pada umumnya. 


\section{METODE PENELITIAN}

\section{Bahan Penelitian}

Tabel 1. Bahan Penelitian

\begin{tabular}{|c|c|c|c|}
\hline No. & $\begin{array}{l}\text { Nama } \\
\text { Bahan }\end{array}$ & Jumlah & Keterangan \\
\hline 1 & $\begin{array}{lc}\text { Xbee } & \text { Series } \\
2 & \text { XB24- } \\
27 W I T-004\end{array}$ & 4 & $\begin{array}{l}\text { Komunikasi } \\
\text { wireless }\end{array}$ \\
\hline 2 & $\begin{array}{l}\text { Xbee } \\
\text { Adapter }\end{array}$ & 1 & $\begin{array}{l}\text { Penghubung } \\
\text { dan } \\
\text { pengkonfigurasi } \\
\text { Xbee dengan } \\
\text { PC }\end{array}$ \\
\hline 3 & $\begin{array}{l}\text { Kabel } \\
\text { RS232 }\end{array}$ & 1 & $\begin{array}{l}\text { Penghubung } \\
\text { Xbee dengan } \\
\text { Arduino }\end{array}$ \\
\hline 4 & $\begin{array}{l}\text { Xbee Shield } \\
\text { Arduino }\end{array}$ & 1 & $\begin{array}{l}\text { Penghubung } \\
\text { Xbee dengan } \\
\text { Arduino }\end{array}$ \\
\hline 5 & $\begin{array}{l}\text { Xbee } \\
\text { Breakout } \\
\text { Shield }\end{array}$ & 3 & $\begin{array}{l}\text { Papan } \\
\text { perluasan pin } \\
\text { Xbee }\end{array}$ \\
\hline 6 & $\begin{array}{l}\text { Arduino } \\
\text { Uno }\end{array}$ & 1 & $\begin{array}{l}\text { Pusat penerima } \\
\text { dan penyimpan } \\
\text { data } \\
\text { komunikasi }\end{array}$ \\
\hline 7 & $\begin{array}{l}\text { Sensor MQ- } \\
2\end{array}$ & 3 & Sensor Asap \\
\hline 8 & $\begin{array}{l}\text { Sensor } \\
\text { LM35 }\end{array}$ & 3 & Sensor Suhu \\
\hline 9 & Button & 3 & Tombol Darurat \\
\hline 10 & Buzzer & 1 & $\begin{array}{l}\text { Alarm Keadaan } \\
\text { Darurat }\end{array}$ \\
\hline 11 & Papan PCB & & $\begin{array}{l}\text { Cetak } \\
\text { rangkaian }\end{array}$ \\
\hline 12 & $\begin{array}{l}\text { Tenol } \\
\text { Solder }\end{array}$ & & $\begin{array}{l}\text { Perekat } \\
\text { komponen }\end{array}$ \\
\hline 13 & Ferit Clorit & & Pelarut tembaga \\
\hline 14 & $\begin{array}{l}\text { Kabel } \\
\text { Jumper }\end{array}$ & & $\begin{array}{l}\text { Penghubung } \\
\text { rangkaian }\end{array}$ \\
\hline 15 & $\begin{array}{l}\text { Kabel } \\
\text { Pelangi }\end{array}$ & & $\begin{array}{l}\text { Penghubung } \\
\text { sensor dengan } \\
\text { PCB }\end{array}$ \\
\hline 16 & Resistor 680 & & Komponen pull \\
\hline
\end{tabular}

\begin{tabular}{|c|c|c|c|}
\hline & ohm & & $\begin{array}{ll}\text { down } & \text { pada } \\
\text { tombol } & \end{array}$ \\
\hline 17 & $\begin{array}{l}\text { White } \\
\text { Housing }\end{array}$ & & $\begin{array}{l}\text { Penghubung } \\
\text { sensor dengan } \\
\text { PCB }\end{array}$ \\
\hline 18 & Lem $G$ & & Perekat \\
\hline 19 & $\begin{array}{l}\text { Baut dan } \\
\text { Mur }\end{array}$ & & Packaging alat \\
\hline 20 & Mata Bor & & Pelubang PCB \\
\hline 21 & Amplas & & Penghalus PCB \\
\hline 22 & $\begin{array}{ll}\text { Baterai LI- } \\
\text { Po }\end{array}$ & 3 & $\begin{array}{l}\text { Sumber daya } \\
\text { node sensor }\end{array}$ \\
\hline 23 & $\begin{array}{l}\text { Papan } \\
\text { Hardboard }\end{array}$ & & $\begin{array}{l}\text { Packaging } \\
\text { system }\end{array}$ \\
\hline 24 & Switch DC & 3 & Saklar \\
\hline 25 & LED & 6 & Indicator \\
\hline 26 & $\begin{array}{l}\text { Diode } \\
\text { 1N4004 }\end{array}$ & 3 & $\begin{array}{l}\text { Pengaman } \\
\text { rangkaian }\end{array}$ \\
\hline 27 & LM317 & 3 & Regulator $3.3 \mathrm{~V}$ \\
\hline 28 & LM7805 & 3 & Regulator $5 \mathrm{~V}$ \\
\hline 29 & 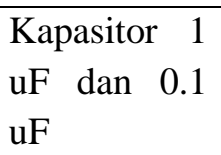 & 6 & $\begin{array}{l}\text { Penyaring } \\
\text { sinyal }\end{array}$ \\
\hline 30 & Trimpot $5 \mathrm{k}$ & 3 & $\begin{array}{l}\text { Pengatur } \\
\text { keluaran } \\
\text { regulator }\end{array}$ \\
\hline 31 & $\begin{array}{l}\text { Resistor } 330 \\
\text { ohm }\end{array}$ & 3 & $\begin{array}{l}\text { Pengatur } \\
\text { keluaran } \\
\text { regulator }\end{array}$ \\
\hline 32 & Black Box & 4 & Packaging node \\
\hline
\end{tabular}

\section{Alat Penelitian}

Tabel 2. Alat Penelitian

\begin{tabular}{|c|c|l|l|}
\hline No. & Jenia Alat & Nama Alat & Keterangan \\
\hline \multirow{2}{*}{1} & \multirow{2}{*}{$\begin{array}{c}\text { Perangkat } \\
\text { Lunak }\end{array}$} & XCTU & $\begin{array}{l}\text { Konfigurasi } \\
\text { modul Xbee }\end{array}$ \\
\cline { 3 - 4 } & & $\begin{array}{l}\text { Arduino } \\
\text { IDE 1.6.5 }\end{array}$ & $\begin{array}{l}\text { Program pada } \\
\text { Arduino }\end{array}$ \\
\cline { 3 - 4 } & Eagle & $\begin{array}{l}\text { Aplikasi } \\
\text { desain jalur } \\
\text { rangkaian }\end{array}$ \\
\cline { 3 - 4 } & & $\begin{array}{l}\text { Visual } \\
\text { Studio C\# }\end{array}$ & $\begin{array}{l}\text { Aplikasi } \\
\text { antarmuka } \\
\text { sistem }\end{array}$ \\
\hline 2 & $\begin{array}{c}\text { Alat } \\
\text { Solder }\end{array}$ & Solder & $\begin{array}{l}\text { Penyambung } \\
\text { komponen }\end{array}$ \\
\hline
\end{tabular}




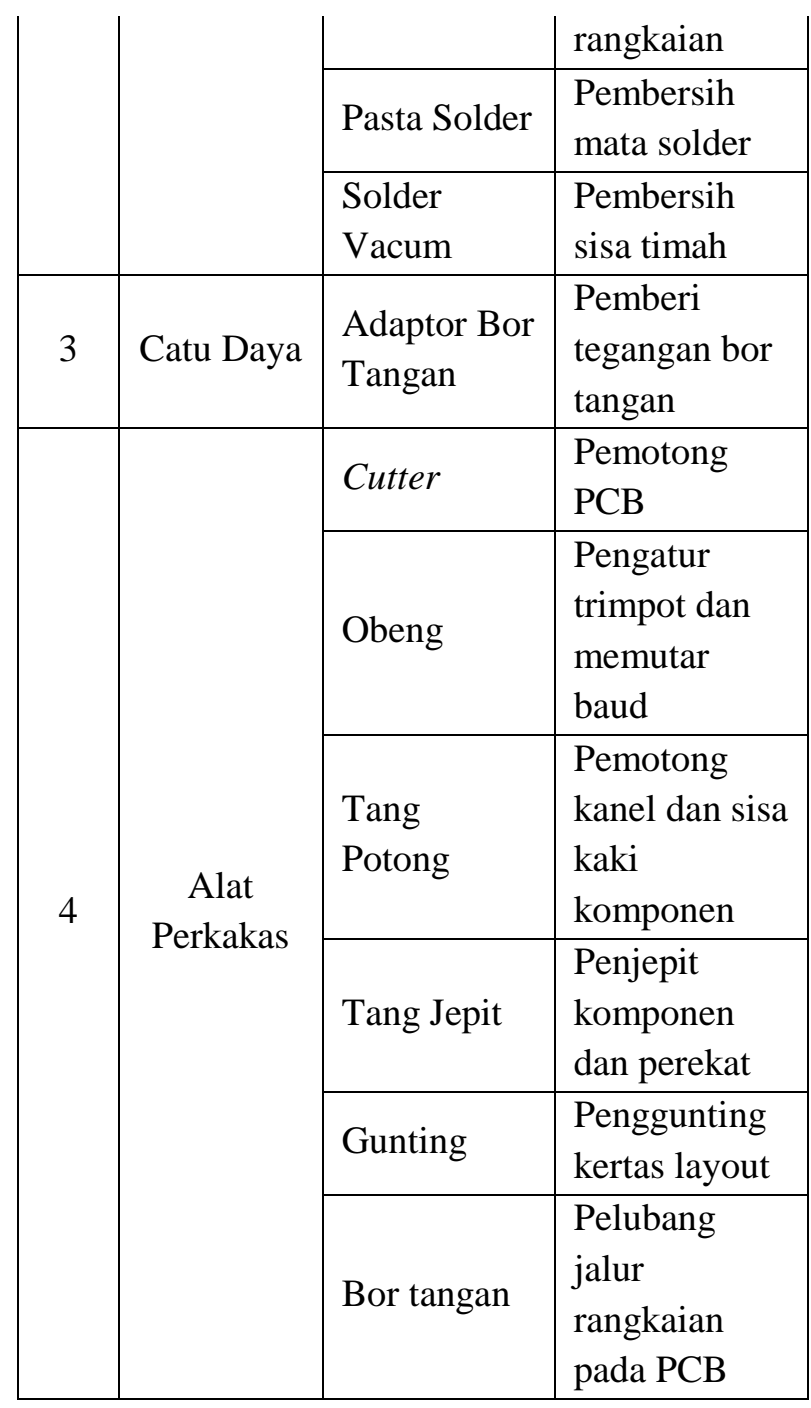

\section{Perancangan Perangkat Keras}

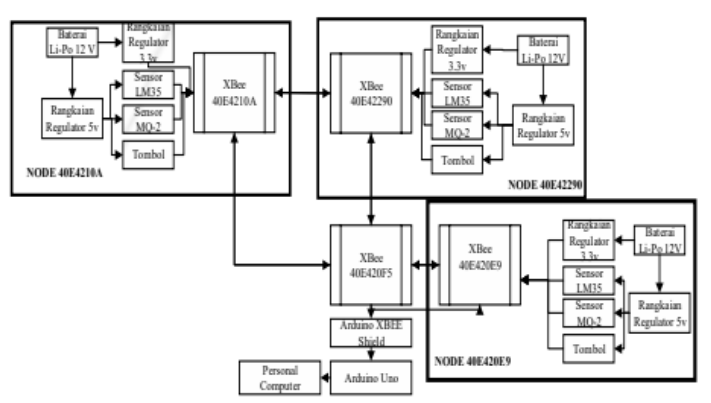

Gambar 1. Diagram Blok Sistem

Sistem terdiri dari 3 buah node sensor yakni node 40E4210A, node 40E42290 dan node 40E420E9 . Node sensor 40E4210A dikonfigurasi sebagai router 1 , node sensor 40E42290 sebagai router 2 dan node sensor
40E420E9 dikonfigurasi sebagai perangkat akhir (end device). Setiap node sensor terdiri dari sensor suhu yakni LM35, asap yakni MQ2 dan tombol. Karena keluaran LM35 berupa nilai analog yang dapat dikonversi menjadi nilai digital (ADC), sensor MQ-2 dikonfigurasi menjadi digital dan tombol berupa nilai digital, maka dapat dihubungkan langsung dengan Xbee tanpa menggunakan mikrokontroller. Hal ini dikarenakan pada Xbee telah tersedia pin I/O ADC dan digital.

Pengiriman dan penerimaan data terpusat pada koordinator yakni menggunakan Xbee 40E420F5. Koordinator terhubung dengan Arduino Uno menggunakan Arduino Xbee shield . Data yang diterima oleh koordinator diolah didalam Arduino Uno agar kemudian ditampilkan dalam Personal Computer (komputer). Setelah data diolah kemudiaan ditampilkan dalam antarmuka (interface) dengan menggunakan Visual Studio.

\section{Perancangan Perangkat Lunak}
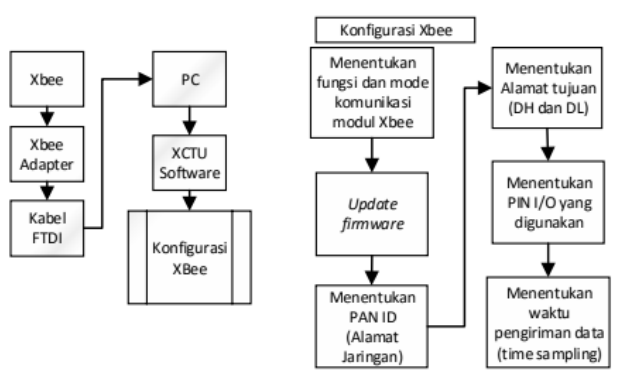

Gambar 2. Perancangan Perangkat Lunak Konfigurasi Modul Xbee

Konfigurasi modul Xbee dibutuhkan Xbee Adapter dan kabel FTDI sebagai perantara antara modul Xbee dengan komputer. Pengkonigurasian modul Xbee menggunakan XCTU software yang dibuat oleh Digi International. Pengkonfigurasian modul Xbee yang pertama dilakukan adalah menentukan fungsi dari modul Xbee yakni sebagai koordinator, router, ataukah perangkat akhir. Untuk menentukan fungsi dari modul Xbee yang digunakan dilakukan dengan cara memperbaharui firmware (update firmware). Penelitian ini menggunakan modul Xbee S2, 
maka pada saat kita update firmware pada saat itu juga kita menentukan jenis mode komunikasi yang digunakan. Setelah itu sangat dibutuhkan untuk membangun sebuah jaringan WSN adalah menentukan alamat jaringan Personal Area Network IDentifier (PAN ID), 35 menentukan alamat tujuan pengiriman data, menentukan fungsi modul Xbee yakni sebagai koordinator, router ataukah perangkat akhir, karena pada penelitian tugas akhir ini tidak menggunakan mikrokontroller pada node sensor dan sensor langsung terhubung dengan modul Xbee maka dalam pengkonfigurasian modul Xbee diperlukan juga untuk menentukan pin I/O yang digunakan.

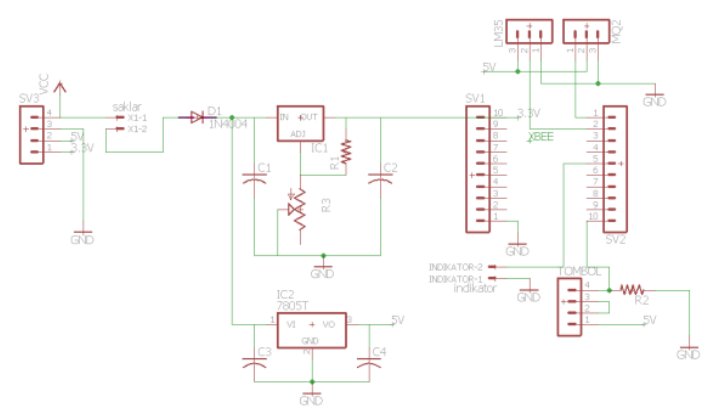

Gambar 3. Rancangan Perangkat Keras Node Sensor



Gambar 4. Implementasi Perangkat Keras Node Sensor

\section{HASIL DAN PEMBAHASAN}

Secara keseluruhan pengujian alat bertujuan untuk mengetahui bahwa alat bekerja dengan cukup baik sehingga menghasilkan sistem yang diinginkan.

Prototipe maket gedung bertingkat dengan node sensor yang berada ditiap ruangannya. Adapun pengujian sistem dilakukan dengan dua tahap. Pengujian setiap node sensor dan pengujian sistem secara keseluruhan

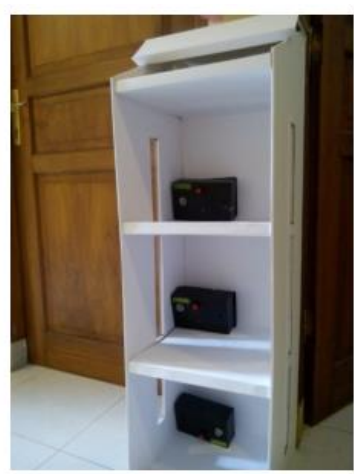

Gambar 5. Prototipe maket gedung bertingkat dengan node sensor

\section{Hasil Pengujian}

\section{Pengujian Sensor Suhu}

Pada pengujian sensor suhu LM35 digunakan sebuah kalibrator yakni termometer ruangan. Adapun hasil pengujiannya dapat dilihat pada Tabel 3. Pengujian sensor suhu LM35 pada node 40E420E9.

Tabel 3. Hasil Pengujian Sensor Suhu LM35

\begin{tabular}{|c|c|c|}
\multicolumn{3}{|c|}{ pada Node 40E420E9 } \\
\hline $\begin{array}{c}\text { Suhu } \\
\text { Ruang } \\
\left({ }^{\circ} \mathbf{C}\right)\end{array}$ & $\begin{array}{c}\text { Suhu } \\
\text { Pembacaan } \\
\left({ }^{\circ} \mathbf{C}\right)\end{array}$ & ADC \\
\hline 28 & 27,72 & 236 \\
\hline 29 & 28,86 & 246 \\
\hline 30 & 29,44 & 251 \\
\hline 31 & 30,62 & 261 \\
\hline 32 & 31,91 & 272 \\
\hline 33 & 32,73 & 279 \\
\hline 34 & 33,31 & 284 \\
\hline 35 & 34,96 & 298 \\
\hline 36 & 35,66 & 304 \\
\hline 37 & 36,72 & 313 \\
\hline
\end{tabular}

\section{Pengujian Sensor Asap}

Pengujian sensor asap dilakukan dengan cara mendekatkan sumber asap pada sensor MQ-2 kemudian data tersebut dikirimkan ke koordinator. Berikut Tabel 4. Hasil Pembacaan sensor MQ-2 pada node 420E420E9. 
Tabel 4. Hasil pembacaan sensor MQ-2 pada node 420E420E9

\begin{tabular}{|c|c|}
\hline Status & Hasil Pembacaan \\
\hline Ada Asap & 1 \\
\hline Tidak Ada Asap & 0 \\
\hline
\end{tabular}

\section{Pengujian Efektifitas Jarak}

Pengujian efektifitas jarak node sensor 40E420E9 dilakukan untuk menguji sejauh mana node sensor 40E420E9 dapat mengirimkan data terhadap koordinator. Berikut Tabel 5. hasil pengujian efektifitas jarak tempuh node sensor 40E420E9.

Tabel 5. Hasil Pengujian Efektifitas Jarak Node40E420E9

\begin{tabular}{|c|c|}
\hline Jarak (m) & Status Data \\
\hline 4 & Terkirim \\
\hline 8 & Terkirim \\
\hline 12 & Terkirim \\
\hline 16 & Terkirim \\
\hline 20 & Terkirim \\
\hline 24 & Terkirim \\
\hline 28 & Terkirim \\
\hline 32 & Terkirim \\
\hline 36 & Terkirim \\
\hline 40 & Tidak Terkirim \\
\hline
\end{tabular}

\section{Hasil Pembacaan Arduino}

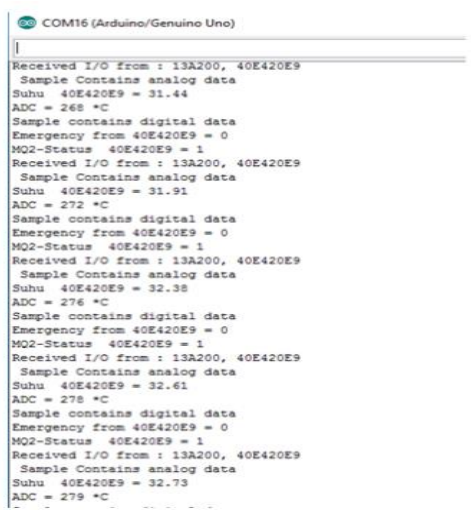

Gambar 6. Hasil Pembacaan Node 40E420E9 Pada Serial Monitor

\section{Hasil Pengujian Sistem}

Pengujian sistem dilakukan dengan dua tahap yakni pengujian komunikasi data dengan Zigbee Mesh Network dan pengujian sistem secara keseluruhan. Pengujian ini bertujuan untuk menentukan penempatan node sensor yang efektif pada Zigbee Mesh Network secara nyata. Percobaan dilakukan sebanyak 4 kali. Berikut hasil dari salah satu percaobaan. Percobaan 1

Tabel 5. Hasi Percobaan 1

\begin{tabular}{|c|c|c|}
\hline Node & Status & Lokasi \\
\hline 40E420E9 & Aktif & Lantai 3 Ruang 2 \\
\hline 40E42290 & Aktif & Lantai 3 Ruang 1 \\
\hline 40E4210A & Aktif & Lantai 2 Ruang 1 \\
\hline $\begin{array}{c}\text { 40E420F5 } \\
\text { (Koordinator) }\end{array}$ & Aktif & Tangga \\
\hline
\end{tabular}

Tabel 6. Data Hasil Pencuplikan 10 Data Percobaan 1

\begin{tabular}{|c|c|c|}
\hline No & Data & \\
\hline 1 & 7E0014920013A20040E420E9E08C0201 & 02000100FDOB \\
\hline 2 & 7E0014920013A20040E4210ABF460201 & 02000100 EC61 \\
\hline 3 & 7E0014920013A20040E420E9E08C0201 & 02000100FDOB \\
\hline 4 & 7E0014920013A20040E4210ABF460201 & 02000100 EC61 \\
\hline 5 & 7E0014920013A20040E42290342F0201 & 020000021156 \\
\hline 6 & 7E0014920013A20040E420E9E08C0201 & 02000100FDOB \\
\hline 7 & 7E0014920013A200 40E42290342F0201 & $020000020 F 58$ \\
\hline 8 & 7E0014920013A20040E4210ABF460201 & 02000100 EC61 \\
\hline 9 & 7E0014920013A20040E4210ABF460201 & 02000100ED60 \\
\hline 10 & 7E0014920013A20040E420E9E08C0201 & 02000100FDOB \\
\hline
\end{tabular}

\section{Tampilan Pengujian Sistem}

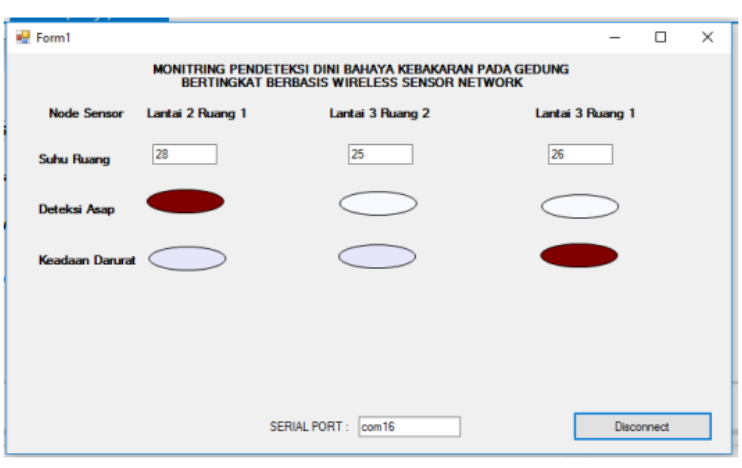

Gambar 7. Pengujian Tampilan Antarmuka

\section{Analisa Data}

Analisa data dilakukan untuk membuktikan kebenaran antara teori dasar dengan data hasil yang diperoleh secara nyata. Analisa data berupa perhitungan atas data yang diperoleh dan pada penelitian ini dilakukan analisa data terhadap hasil dari pembacaan suhu pada setiap node sensor. Karena hasil pembacaan sensor suhu yang dikirimkan ke 
koordinator berupa ADC, maka digunakan persamaan sebagai berikut :

$$
\text { Vout } L M 35=\frac{\text { data } A D C}{\text { maks_dataADC }} \times \text { Vref }
$$

\section{Keterangan :}

Data $\mathrm{ADC}=$ hasil pembacaan adc

Maks_dataADC $=1023$

Vref $=$ tegangan referensi $(\mathrm{V})$

Vout LM35 = hasil pembacaan sensor LM35 $(\mathrm{mV})$

\section{Grafik Hasil Pembacaan}



Gambar 8. Hasil Pembacaan Suhu Node Sensor

Dari Gambar 8. dapat dilihat bahwa hasil pembacaan suhu pada setiap node sensor bersifat linier. Semakin tinggi suhu ruang maka hasil pembacaan suhu pada node sensor juga semakin tinggi.

\section{Pembahasan Dan Diskusi}

Suhu dan asap sangat erat kaitannya dengan bahaya kebakaran maka dari itu pada penelitian ini digunakan sensor suhu dan asap untuk mendeteksi adanya kemungkinan bahaya kebakaran pada suatu ruang. Pada suhu ruang standar atau suhu kamar normal yakni sebesar $25-30^{\circ} \mathrm{C}$. Akan tetapi, apabila suhu kamar tersebut naik semakin tinggi maka suhu kamar tersebut menjadi tidak normal dan hal tersebut harus diwaspadai karena dapat berakibat menimbulkan kebakaran.

Selain suhu yang meningkat adanya asap pembakaran, bisa disebabkan puntung rokok, kompor yang lupa dimatikan berjam- jam, atau bahkan kabel listrik yang konslet dapat menjadi sebuah indikasi penyebab kebakaran.

Pada penelitian yang dilakukan oleh Arkan (2014), teah dikembangkan sebuah sistem deteksi kebakaran menggunakan teknologi Wireless Sensor Network. Penekanan dalam penelitian ini terletak pada proses transfer data dari sensor suhu, sensor titik api dan sensor asap ke pusat kontrol. Transfer data yang dimaksudkan dalam hal ini adalah kecepatan transfer data dan kekuatan sinyal ($\mathrm{dBm}$ ) dengan jarak terjauh yang bisa dijangkau oleh Zigbee tersebut. Sensor suhu yang digunakan ialah sensor LM35DZ, untuk sensor titik api menggunakan kombinasi sensor LM358N dan photodioda sedangkan untuk sensor asap menggunakan kombinasi sensor LM358N dan LDR. Modul komunikasi yang digunakan untuk membangun sistem ini ialah Xbee Pro S1 dengan mode komunikasi yaitu Application Programming Interface (API). Sistem deteksi kebakaran yang dibangun menggunakan 3 buah node yang mana 2 node sebagai end device yang berfungsi mengambil data sensor pada detektor dan 1 node sebagai koordinator yang terhubung langsung dengan komputer. Hasil dari pemantauan suhu ditampilkan pada komputer dengan sebuah antarmuka yang dibangun menggunakan Visual Basic 6.0. Hasil dari pengujian sistem ialah sistem dapat dibangun dengan baik pada model join a network yaitu antara koordinator dan end device pada jarak terjauh dalam ruangan sebesar 72,8 meter dengan kekuatan sinyal 73,67 dBm. Kesimpulan yang dapat diperoleh dari penelitian ini adalah jarak terjauh dari modul Xbee Pro S1 untuk komunikasi data didalam ruangan sebesar 70,8 meter.

Pada penelitian yang dilakukan oleh Susana dkk (2015), telah diteliti sebuah sistem WSN yang digunakan untuk mendeteksi kebakaran berupa api dan asap. Sensor api dan asap yang dihubungkan ke mikrokontroler Arduino Uno hasil pendeteksian kemudian dikirimkan melalui sms kepada pemadam kebakaran dan tim investigasi pemadam 
kebakaran. komunikasi GSM sistem ini dibuat dengan batasan ruangan sebanyak 3 ruang dengan ukuran sebesar $15 \times 15 \times 15 \mathrm{~cm}$, penemptan sensor tidak diperhitungkan dan sensor yang digunakan ialah sensor api dan asap.

Paling banyak penyebab kebakaran pada rumah tangga disebabkan oleh konsletnya kabel listrik maka dari itu selain mengembangkan alat deteksi kebakaran menggunakan sensor suhu dan asap, pada penelitian ini juga dikembangkan pengurangan kabel pada alat yang dikembangkan. Pengurangan tersebut dilakukan dengan memanfaatkan konsep Wireles Sensor Network. Pengembangan dari Wireles Sensor Network dalam berbagai bidang saat ini sangatlah pesat karena efektifitas dan pengurangan biaya serta energi yang sangat signifikan dalam penggunaanya. Karena tidak menggunakan kabel sebagai komunikasi datanya maka sistem ini menjadi portable dan untuk penempatan dari setiap sensor node sangat perlu diperhatikan agar pembacaan data juga maksimal. Seperti sensor asap MQ2, apabila terdapat asap dari samping maka pembacaan datanya sangat tidak sensitif, lain halnya apabila asap yang dideteksi berasal dari depan sensor.

Dari penelitian ini telah dilakukan beberapa percobaan dan pengambilan data untuk mengetahui keberhasilan dari sistem yang telah dikembangkan seperti yang tertera pada data hasil diatas. Pada pengujian sensor suhu, data yang dihasilkan dari setiap node sensor memang sedikit terjadi perbedaan pembacaan data pada termometer ruang dan sensor suhu akan tetapi itu merupakan hal yang wajar karena dalam pembacaan termometer terdapat kemungkinan terjadi kesalahan pada pengelihatan garis alkohol dan selain itu pada pembacaan sensor dilakukan pengiriman data dari pembacaan setiap 5 detik sehingga dapat menyebabkan ketidaksamaan pembacaan data namun secara keseluruhan data yang didapatkan dari sensor suhu bersifat linier.

Pada pengujian sensor asap MQ-2, data yang terbaca bersifat digital karena pada penelitian ini memanfaatkan pin DO dari MQ-2 untuk mendeteksi ada atau tidaknya asap didalam ruangan. Pada pengujian ini didapatkan hasil apabila terdapat asap maka DO bernilai 0 dan apabla tidak terdapat asap maka DO bernilai 1. Pada sistem ini juga dilengkapi dengan tombol, yang mana tombol tersebut difungsikan sebagai tombol darurat. Apabila didalam ruangan terdapat seseorang yang kondisinya dalam keadaan darurat maka dapat menggunakan tombol tersebut untuk meminta bantuan. 70

Setelah pengujian setiap sensor, dilakukan pengujian efektifitas jarak setiap node sensor untuk mengetahui seberapa jauh node sensor dapat terhubung dengan koordinator. Di dalam datasheet Xbee S2, modul Xbee S2 mampu menempuh jarak sejauh $40 \mathrm{~m}$ akan tetapi dari pengujian ini, pada saat jarak node sensor sejauh 40m data tidak dapat terkirim. Hal ini dapat disebabkan oleh beberapa faktor lingkungan yang ada didaerah pengujian.

Keuntungan yang didapatkan dari Zigbee Mesh Network adalah reliable atau data yang dikirimkan dalam jaringan pasti akan sampai pada koordidator. Hal ini telah dibuktikan dengan melakukan percobaan pada sistem jaingan dengan menonaktifkan salah satu node sensor.

Dari hasil percobaan tersebut, walaupun terdapat salah satu node sensor yang tidak aktif hal itu sama sekali tidak mempengaruhi proses pengiriman data dalam jaringan. Data yang dikirimkan dari node yang aktif dapat diterima oleh koordinator. Proses pengirman data yang dilakukan menggunakan mode komunikasi API pada koordinator. Maka dari itu data yang dikirimkan berupa paket data dalam satuan Hexadesimal. Data yang dikirimkan kemudian diolah oleh Arduino Uno agar dapat terhubung dengan antarmuka. Pada tampilan antarmuka, data yan telah diolah oleh arduino ditampilkan dalam bentuk visual, sehingga pengguna lebih mudah memahami informasi yang didapatkan. Selain itu dari tampilan antarmuka, pengguna dapat 
mengetahui titik lokasi asal mulanya indikasi kebakaran terjadi dari jarak jauh.

\section{KESIMPULAN}

Dari penelitian yang sudah dilakukan oleh peneliti, dapat disimpulkan sebagai berkikut :

1. Sistem peringatan dini kebakaran berbasis zigbee mesh network telah dapat dibangun dari jarak jauh dan hemat energi.

2. Alamat PAN ID pada node sensor dalam satu jaringan harus sama agar dapat saling berkomunikasi.

3. Dalam satu jaringan hanya memiliki satu koordinator dan pada koordinator harus menggunakan mikrokontroller.

4. Pembangunan sistem sensor jaringan nirkabel dengan menggunakan topologi Mesh pada Zigbee Mesh Network Xbee S2 dapat dibangun dengan mengkonfigurasi alamat $\mathrm{DH}=0$ dan $\mathrm{DL}=0$ pada XCTU.

5. Node sensor yang tidak aktif tidak mempengaruhi pengiriman data pada node sensor yang aktif.

6. Komunikasi yang digunakan oleh koordinator harus dalam mode komunikasi API sedangkan node sensor dapat menggunakan AT maupun API.

\section{DAFTAR PUSTAKA}

[1] Abad, M., \& Jamali, M. (2011). Modify LEACH algorithm for Wireless Sensor Network. International Journal of Computer Science, Vol. 8 No.1.

[2] Afreen, S., \& Begum, I. (2016). Wireless Sensor Network and Web Based Information System for Asthma Trigger Factors Monitoring. International Journal \& Magazine of Engineering, Technology, Management and Research , 334.

[3] Algoiare, O. T. (2014). Design and Implementaton of Intelligent Home Using GSM Network. Ankara: Cankaya University.

[4] Amalina, E. N., dkk (2013). Perbandingan Topologi WSN(Wireless Sensor Network untuk Sistem Pemantauan Jembatan. Smart-
Green Technology in Electrical and Information. Bali: Universitas Udayana.

[5] Krishnamurti, K.., dkk. (2015). Arduino Based Weather Monitoring System. International Journal of Engineering Research and General Science, Vol.3, Issue 2.

[6] Sugiarto, B. (2010). Perancangan Sistem Pengendalian Suhu pada Gedung Bertingkat dengan Teknologi Wireless Sensor Network. Jurnal Ilmiah Teknik Mesin Cakra M , 62-68.

[7] Susana, Ratna., dkk. (2015). Implementasi Wireless Sensor Network Prototype Sebagai Fire Detector menggunakan Arduino Uno. Jurnal Elektro Telekomunikasi Terapan . Instruments, Texas (2016). LM35 Precision Centigrade Temperature Sensors. Texas Instruments Incorporated.

[8] Utomo, B. T., \& Saputra, D. S. (2016). Simulasi Sistem Pendeteksi Polusi Ruangan Mengunakan Sensor Asap dengan Pemberitahuan Melalui SMS(Short Message Service) dan Alarm Berbasis Arduino. Jurnal Ilmiah Teknologi dan Informasia ASIA(JITIKA) , 56. 